\title{
"Taking our blindfolds off": acknowledging the vision of First Nations peoples for nursing and midwifery
}

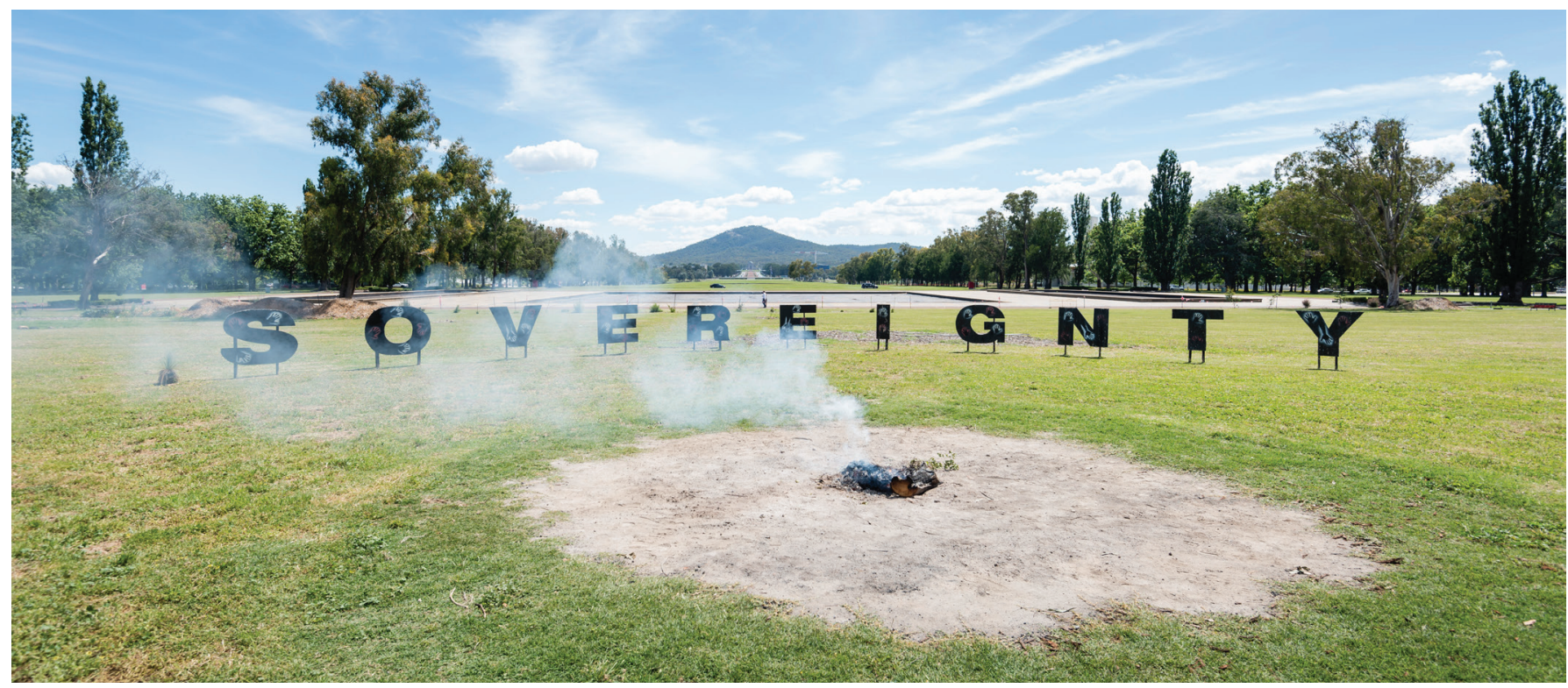

We acknowledge the sovereignty of First Nations Peoples across the Earth as the traditional custodians of Country and

respect their continuing connection to culture, community, land, waters, and sky. We pay our respect to Elders past and present and in particular to those who led the way, allowing us to realise our own aspirations to be healers and carers, ushering our people from and to the Dreaming. ${ }^{1}$

"You need to take your blindfolds off and come back to the fire". These were the words of a First Nations Elder and a custodian of the sacred fire speaking to Congress of Aboriginal and Torres Strait Islander Nurses and Midwives (CATSINaM) delegates and educational researchers during a recent visit to the Aboriginal Tent Embassy in Canberra. These words called to us to remember and to acknowledge our ways of knowing, doing and being as First Nations health professionals and researchers. ${ }^{2}$ They also called to all who were present to critically reflect on our professional stance and practices as nurses, midwives and researchers in the light of the fire. This editorial responds to and draws on the words of a First Nations Elder, to remind us all of the importance of who we are, where we have come from and our place, position, and traditional practices within the Australian nursing and midwifery profession.

These words are a reminder of the importance of our shared role and responsibility to continue to challenge racism and oppressive practices in Australian healthcare for transformation and for better health outcomes for First Nations Peoples. Decolonising nursing and midwifery research and education is a clear transformational reform process to address oppressive practices and racism including attitudes, ignorance and bias, generalisations, assumptions,

\footnotetext{
* Please note the term "First Nations peoples" is used here to be respectful and inclusive of all Indigenous Peoples whose countries and nations have been and still are impacted by colonisation. The First Peoples of Australia represent over 500 Aboriginal and Torres Strait Islander nations who have never ceded sovereignty. In this editorial we use the term First Nations peoples to specifically refer to the peoples from the First Nations of Australia.
} 
uninformed opinions and commit to developing and embedding cultural safety in the nursing and midwifery professions.

As a collective of First Nations nurses and midwives, we acknowledge the distinctive countries we belong to that position our identities, experiences, roles, rights and responsibilities as educational researchers in nursing and midwifery. Collectively, we represent a growing community of researchers involved in decolonising nursing and midwifery research and professional education, united by a deep conviction to work together to counteract the repressive ways that sustain deficit approaches towards First Nations patients and nurses and midwives in education, health, and research contexts.

The Elder's words reminded us that as nursing and midwifery professionals we needed to "take off our blindfolds" to be able to see what we may not be able to see yet. What he reminded us about was the way we view or approach the ethics of care as both First Nations and the wider nursing and midwifery workforce and spoke to the ways in which racialising First Nations peoples in education, research or in clinical practice is still the norm in Australia.

We are grateful for the invitation to write the first guest editorial for 2021 for the Australian Journal of Advanced Nursing, and seek to take off our blindfolds and come back to the fire to build better and effective relationships within the Australian nursing and midwifery professions toward a shared commitment to cultural safety praxis. In particular, we seek to examine the nursing and midwifery professional socialisation that informs the lens through which nurses and midwives view First Nations people's rights to culturally safe healthcare. In doing so we acknowledge that current curriculum innovations involving First Nations peoples, their health needs, and our roles in addressing them in nursing and midwifery, present a defining challenge for our professions at this time.

In 1988 the nursing profession was first introduced to the concept of cultural safety through the work of Maori Nurse Irihapeti Ramsden and her work has now changed nursing and midwifery education and practice. ${ }^{3}$ At the same time, First Nations nurses in Australia were establishing a collective identity and voice in research and healthcare through CATSIN, the Congress of Aboriginal and Torres Strait Islander Nurses. Almost 25 years later the 2020 International Year of the Nurse and Midwife saw an Australian First Nations collaboration with over 100 nursing and midwifery leaders issue a call to action advocating for a unified professional response to the Black Lives Matter movement, highlighting the continuing inequities in the Australian healthcare system. To heed the words of our Elders and remove any blindfolds we call for all of us to look with fresh eyes at the way nursing and midwifery education, research and practice can perpetuate these unjust practices under our watch if left unchecked. 4,5
In this editorial, we outline why we need to take off our professional blindfolds and look at the elephant in the room in nursing and midwifery. As health professionals, we need to see how our education and research theories, methods and methodologies socialise our clinical worldview and the way our respective professions relate to Australia's First Peoples. This means being able to see and acknowledge the impact of our own cultural backgrounds on what we bring into quality and standards in nursing and midwifery care. We also need to make a commitment to transformative approaches in the life-long learning journey that growing culturally safe nurses and midwives entails. To enable this, we propose that Indigenist and decolonising ethics and approaches in research, education, the academy and in healthcare are critical tools to expedite First Nations people's right to access culturally safe care from, and within, the nursing and midwifery profession. ${ }^{6-8}$

As a research collective, we are united by the shared values and principles embedded in contemporary Indigenist and decolonising research approaches. Decolonising and Indigenist approaches refocus the object of the professional gaze more towards the professions, institutions and structures that frame First Peoples as objects in research and care.6,9 Applying First Peoples knowledges and lived experiences to inform research praxis is challenging to articulate and frame in research and requires addressing core tensions and differences in the assumptions that underpin research. It does this by consciously and critically engaging with the need to transform the discourse, or the way we view, talk about, and create First Nations health. ${ }^{10,11}$ For First Nations researchers and educators in nursing and midwifery this often involves addressing how our bodies, families and communities are perceived and storied in First Nations health research. ${ }^{12-14}$

Cultural safety is both a philosophy and strategy for reducing professional and institutional racism. ${ }^{15}$ We argue that health practitioners have a responsibility to employ critical consciousness to developing strategic frameworks that promote and make space for a culturally safe working environment, and safe healing environment for Aboriginal and Torres Strait Islander people. History informs us that broader nurses and midwives in the not so distant past practiced as agents for government control. Complicit in enforcing government assimilation policies these health practices were discriminatory and experienced by First Nations nurses, midwives and patients as racism. ${ }^{16,17}$ While cultural safety training is mandatory in nursing and midwifery education, the effectiveness of this in practice is unclear. There is currently a lack of published literature to document the impact of cultural safety curriculum innovations and the reduction of health inequities through creating safe work environments.

Cultural safety is both a right for Aboriginal and Torres Strait Islander peoples to experience in nursing and midwifery and in healthcare and a responsibility for health nurses and 
midwives to uphold and commit to. Many untold stories of the role played by nurses and midwives in government control and assimilation policies underpin the history of nursing and midwifery amongst First Nations peoples in Australia and the racism that First Nations nurses, midwives and patients continue to experience within healthcare. ${ }^{16-17}$

Our collective work is focussed on how cultural safety is researched, monitored and evaluated, as a critical component of patient safety inextricably linked to clinical safety, in Australia and importantly one not possible without the other. Our approach to cultural safety research also involves being culturally safe researchers. We seek to do this by being critically conscious and developing robust research theory and methodology that accommodate and value different ways of knowing, being and doing, and build a sense of ownership and community through research practice partnerships that contribute to the strategic goals of CATSINaM. Advocating and employing Indigenist and decolonising research approaches enables us to navigate a range of tensions that are common in cross cultural research and evaluation contexts. These tensions include:

- Balancing multiple accountabilities -

- To the families and communities who as First Nations peoples we are accountable to.

- To the Nursing and Midwifery professions that as Nurses and Midwives we are accountable to.

- To Universities and Schools of Nursing and Midwifery that as Nursing and Midwifery Academics we are accountable to.

- To health organisations that as health professionals we are accountable to.

- Upholding cultural responsibilities and obligations; and

- Addressing differing expectations of research.

The research we collectively do involves the broader cultural and social determinants of health. Including Indigenous, nurses and midwives' unique ways of knowing, doing and being in this work helps us navigate complex health spaces for our communities and for our non-Indigenous colleagues grappling with understanding the impact of their cultural backgrounds on nursing and midwifery education and research. As a collective we advocate for an approach within Indigenous nurses and midwives research that aligns with the three fundamental and interrelated imperatives of Indigenist research namely:

- resistance as the emancipatory imperative in research

- political integrity in Indigenous research

- privileging Indigenous voices in Indigenist research ${ }^{18}$

Our approach to research also aligns with the values and principles that guide the ethical conduct of research with Aboriginal and Torres Strait Islander peoples and communities in Australia of the National Health and Medical Research Council (NHMRC) and the Australian Institute of Aboriginal and Torres Strait Islander Studies (AIATSIS).
While we acknowledge these values and principles in research, we call for others to recognise and understand that these approaches hold value for the professional aspirations of nursing and midwifery education, and research.

In growing our research and education approach with others, we seek to use our collective Indigenous voice to raise and address critical health issues and create a legacy in Indigenous nursing and midwifery research. This is in part political, necessarily so - but it is also personal because of our position, responsibility and accountability to our communities. The International Year of the Nurse and Midwife 2020 marked a year of great change and challenges for the nursing and midwifery workforce, we have experienced social and health upheavals that have shocked and called us to attention, and reflect on who we are as nurses and midwives collectively. We can no longer be silent on issues that are unjust and oppressive.

Our Elders call for us all to "take off our blindfolds" and "come back to the fire" and they remind us to acknowledge our shared responsibility to be transformational in how we story and conduct research in nursing and midwifery. This editorial marks the beginning of developing our community of practice as First Nations nurses and midwives, educators, practitioners and researchers. We invite our nursing and midwifery colleagues to also return to the fire and critically reflect on what its light reveals for the nursing and midwifery profession and for those within our care. We urge you to not remain silent but to join us to speak into the silence that surrounds the tacit acceptance of culturally unsafe care.

Prof Juanita Sherwood Wiradjuri

Office of Indigenous Engagement, Charles Sturt University, Bathurst, New South Wales, Australia

Prof Roianne West Kalkadoon and Djaku-nde peoples School of Nursing and Midwifery, Griffith University, Brisbane, Queensland, Australia

Dr Lynore Geia Bwgcolman, culturally linked to Kalkadoon, Birri Gubba and the Torres Strait

College of Healthcare Sciences, James Cook University, Douglas, Queensland, Australia

Ali Drummond Meriam, Wuthathi School of Nursing, Queensland University of Technology, Brisbane, Queensland, Australia

Dr Tamara Power Wiradjuri

Susan Wakil School of Nursing, Faculty of Health and Medicine, University of Sydney, New South Wales, Australia

Dr Lynne Stuart Mandandanji

School of Nursing, Midwifery and Paramedicine, University of the Sunshine Coast, Queensland, Australia

Associate Prof Linda Deravin Wiradjuri

Faculty of Science, Charles Sturt University, Bathurst, New South Wales, Australia 


\section{REFERENCES}

1 Power T, Geia L, Adams K, Drummond A, Saunders V, Stuart L, et al. Beyond 2020: addressing racism through transformative indigenous health and cultural safety education. J Clin Nurs. 2020; Available from: https://doi.org/10.1111/jocn.15623

2 Martin K, Mirraboopa B. Ways of knowing, being and doing: a theoretical framework and methods for indigenous and indigenist re-search. J Aust Stud. 2003; 27(76): 203-14.

3 Ramsden I. Cultural safety. N Z Nurs J. 1990; 83(11):18-9.

4 Rigney LI. Indigenous Peoples' Wisdom and Power. Indigenist research and Aboriginal Australia. Bodmin: United Kingdom Ashgate Publishing Limited; 2006; 32-50.

5 Sherwood J. Who is not coping with colonization? Laying out the map for decolonization. Australas Psychiatry. 2009; 17(1_suppl):S24-S27. Available from: https://doi. org/10.1080/10398560902948662

6 Sherwood J, Edwards T. Decolonisation: a critical step for improving Aboriginal health. Contemp Nurse. 2006; 22(2): 178-90. Available from: https://doi.org/10.5172/ conu.2006.22.2.178

7 Sherwood J. Do no harm: decolonising Aboriginal health research [dissertation]. Sydney: University of New South Wales; 2010. [cited 2021 Jan 26] Available from: http://unsworks.unsw. edu.au/fapi/datastream/unsworks:8457/SOURCE02?view=true

8 Sherwood J, Anthony T. Ethical Conduct in Indigenous Research: It's Just Good Manners. In: George L, Tauri J, Te Ata o Tu MacDonald L, editors. Indigenous Research Ethics: Claiming Research Sovereignty Beyond Deficit and the Colonial Legacy; 2020.

9 Rigney LI. A first perspective of Indigenous Australian participation in science: framing Indigenous research towards Indigenous Australian intellectual sovereignty. Aboriginal Research Institute, University of South Australia. Adelaide. 2001. [cited 2021 Jan 26]. Available from: https://cpb-apse2.wpmucdn.com/thinkspace.csu.edu.au/dist/c/3891/ files/2020/10/LI Rigney First perspective.pdf

10 Fforde C, Bamblett L, Lovett R, Gorringe S, Fogarty B. Discourse, deficit and identity: Aboriginality, the race paradigm and the language of representation in contemporary Australia. Media Int Aust. 2013; 149(1): 162-73. Available from: https://doi.org/10.1177/1329878X1314900117

11 Fogarty W, Bulloch H, McDonnell, S, Davis, M. Deficit discourse and Indigenous health: how narrative framings of Aboriginal and Torres Strait Islander people are produced in policy. The Lowitja Institute. Melbourne. 2018. [cited 2021 Jan 26]. Available from: https://www.lowitja.org.au/content/Document/LowitjaPublishing/deficit-discourse.pdf

12 Bainbridge R, Tsey K, McCalman J, Kinchin, I, Saunders, V, Lui, FW, et al. No one's discussing the elephant in the room: contemplating questions of research impact and benefit in Aboriginal and Torres Strait Islander Australian health research. BMC Public Health. 2015; 15(1): 696-706. Available from: https://doi.org/10.1186/s12889-015-2052-3

13 Chandna K, Vine MM, Snelling S, Harris R, Smylie J, Manson, $H$. Principles, approaches, and methods for evaluation in Indigenous contexts: a grey literature scoping review. Can J Program Eval. 2019; 34(1): 21-47. Available from: https://doi.org/10.3138/cjpe.43050
14 Australian Government Productivity Commission. Indigenous evaluation strategy. Australian Government Productivity Commission. Melbourne. 2019. [cited 2021 Jan 26] Available from: https://www.pc.gov.au/inquiries/current/indigenousevaluation/issues/indigenous-evaluation-issues.pdf

15 Ramsden I. Cultural safety and nursing education in Aotearoa and Te Waipounamu [dissertation]. Wellington: Victoria University of Wellington; 2002. [cited 2021 Jan 26] Available from: https://croakey.org/wp-content/uploads/2017/08/ RAMSDEN-I-Cultural-Safety Full.pdf

16 Cox L. Fear, trust and Aborigines: The historical experience of State institutions and current encounters in the health system. Health History. 2007; 9(2): 1-23. [cited 2021 Jan 26] Available from: https://eprints.qut.edu.au/26721/1/Cox Health and History 08 FINAL.pdf

17 Forsyth S. Telling stories: nurses, politics and Aboriginal Australians circa 1900-1980s. Contemp Nurse. 2007; 24(1): 33-44. Available from: https://doi.org/10.5172/ conu.2007.24.1.33

18 Rigney LI. Internationalization of an Indigenous anticolonial cultural critique of research methodologies: a guide to Indigenist research methodology and its principles. Wicazo sa review. 1999; 14(2): 109-21. 